\title{
Humanities
}

\section{Drifting Away}

Carolyn Reardon'

'Class of 2015, Faculty of Medicine, Dalhousie University

Today is a "good day." At least right now it is, early in the morning. Sometimes it seems my good days drift into bad days before I can grab on and anchor myself against the tide rushing out, taking with it words from the tip of my tongue, names that had been long adhered to faces. And I'm left grappling, searching, fumbling as if in the dark.

Some days, I can't say exactly how long I've been here. On my good days, I remember our old restored beach house just fine, but I know that's no longer home. On my bad days, I'm homesick, although I can't quite conjure an image of which home I long for. Perhaps the beach house, sometimes barely a fuzzy outline, dotted with the clouded faces of our children at different ages. Perhaps my rural family practice, since that was where I truly felt at home. That is, of course, until the bad days started creeping in, and it became so hostile and unfamiliar. The whispers of the staff, the bewildered, accusatory looks of the patients, and me, not quite certain of what was real or imagined. Yes, I think that's how it happened. I most often think of our first apartment, above my father's store, where we lived in my first years of practice. Where we first noticed him slipping; the misplaced items, then the finances in ruins. Some days, some hours, really, it seems not so far away, that time and place.

How naïve I'd been then, as a young man, checking my own father into a place just like this. To think I would somehow be immune. How embarrassing; a physician, formally trained in the neurosciences, and less formally, but never the less experienced, in the intricate layers of human behaviour, from years immersed in the lives of my patients. Friends and neighbours, really. Steeped in the daily fumblings of human imperfection, I should have known better.

But I know now, on my good days, that deep down I truly believed it. That I could cultivate a life so meaningful it would just stick. That I could acquire enough knowledge, that I could see enough beauty, that I could travel to enough remote corners of the world, I would build a life so interesting, so important, it could never be forgotten. The memories could never drift away, they would be anchored by the richness of the sunsets watched, the foreign streets navigated, the waters swam in, and the babies delivered. I could spread myself out like the ocean, into the intricate voids in the lives of my patients, into the mysterious holes of scientific knowledge, so that when the tide ebbed, I would pool there, remaining. And when my own bad days started, I was shocked at my dismay that my plan hadn't worked. I hadn't even known it was a plan. I had simply believed that I could see clearly enough. That I could love strongly enough.

Looking back, on days when I do look back, I don't think it was arrogance. I think maybe it was just youthful optimism, propped up by an underlying fear it would happen to me, too. That I would be the one staring out the window of the nursing home, day in day out, with a face as blank as a fog bank when my own kids came to see me. On my good days, I mourn for that ignorant optimism and that panicked energy, pushing me to rush, rush. On my bad days, I'm still mourning, although I just can't put my finger on what. My wife? My kids? But the kids come from time to time, I believe.

Why can't I forget to mourn? Why can't these innate feelings drift away, like the names of patients I had seen for over thirty years, and the proper places for the instruments used every day in the office. Drifting, at first just within sight, but then fading until that tiny point on the horizon disappeared.

On my medium days, I think maybe I became saturated, from all the things I rushed to absorb, now seeping out in all directions in a puddle on the floor. Maybe I rushed too much, and didn't absorb them at all. I can't say, now. 